\title{
Proxy Measures for Simplified Environmental Assessment of Manufactured Nanomaterials
}

\author{
Arvidsson, Rickard; Baun, Anders; Furberg, Anna; Hansen, Steffen Foss; Molander, Sverker
}

Published in:

Environmental Science and Technology

Link to article, DOI:

10.1021/acs.est.8b05405

Publication date:

2018

Document Version

Publisher's PDF, also known as Version of record

Link back to DTU Orbit

Citation (APA):

Arvidsson, R., Baun, A., Furberg, A., Hansen, S. F., \& Molander, S. (2018). Proxy Measures for Simplified Environmental Assessment of Manufactured Nanomaterials. Environmental Science and Technology, 52(23), 13670-13680. https://doi.org/10.1021/acs.est.8b05405

\section{General rights}

Copyright and moral rights for the publications made accessible in the public portal are retained by the authors and/or other copyright owners and it is a condition of accessing publications that users recognise and abide by the legal requirements associated with these rights.

- Users may download and print one copy of any publication from the public portal for the purpose of private study or research.

- You may not further distribute the material or use it for any profit-making activity or commercial gain

- You may freely distribute the URL identifying the publication in the public portal 


\title{
Proxy Measures for Simplified Environmental Assessment of Manufactured Nanomaterials
}

\author{
Rickard Arvidsson, ${ }^{*}, \dagger,{ }^{\dagger}$ Anders Baun, ${ }^{\ddagger}$ Anna Furberg, ${ }^{\dagger}$ Steffen Foss Hansen, ${ }^{\ddagger}$ and Sverker Molander ${ }^{\dagger}$ \\ ${ }^{\dagger}$ Division of Environmental Systems Analysis, Chalmers University of Technology, Vera Sandbergs Allé 8, 41296 Gothenburg, \\ Sweden \\ ${ }^{\ddagger}$ Department of Environmental Engineering, Technical University of Denmark, Bygningstorvet, Building 115, 2800 Kongens Lyngby, \\ Denmark
}

\section{Supporting Information}

\begin{abstract}
Proxy measures have been proposed as a lowdata option for simplified assessment of environmental threat given the high complexity of the natural environment. We here review studies of environmental release, fate, toxicity, and risk to identify relevant proxy measures for manufactured nanomaterials (MNMs). In total, 18 potential proxy measures were identified and evaluated regarding their link to environmental risk, an aspect of relevance, and data availability, an aspect of practice. They include socio-technical measures (e.g., MNM release), particle-specific measures (e.g., particle size), partitioning coefficients (e.g., the octanol-water coefficient), and other fate-related measures (e.g., half-life) as well as various ecotoxicological measures (e.g., 50\% effect concentration). For most identified proxy measures, the link

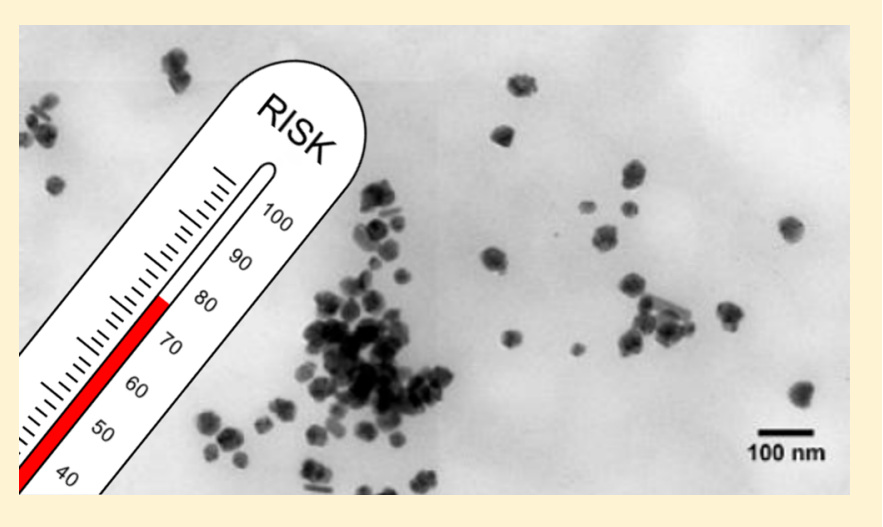
to environmental risk was weak and data availability low. Two exceptions were global production volume and ecotoxicity, for which the links to environmental risk are strong and data availability relatively decent. As proof of concept, these were employed to assess seven MNMs: titanium dioxide, cerium dioxide, zinc oxide, silver, silicon dioxide, carbon nanotubes, and graphene. The results show that none of the MNMs have both high production volumes and high ecotoxicity. Several refinements of the assessment are possible, such as higher resolution regarding the MNMs assessed (e.g., different allotropes) and different metrics (e.g., particle number and surface area). The proof of concept shows the feasibility of using proxy measures for environmental assessment of MNMs, in particular for novel MNMs in early technological development, when data is particularly scarce.
\end{abstract}

\section{INTRODUCTION}

In two sequential papers, Berg and Scheringer ${ }^{1}$ and Scheringer and Berg $^{2}$ wrote about the overcomplexity of the natural environment, stating that the environment cannot be described in a deterministic way. In particular, the risk of chemical substances is therefore difficult to model with any accuracy. As an alternative, they proposed the use of proxy measures, which are observable indicators or variables intended to reduce the complexity of the assessment. Proxy measures thus reflect environmental threat rather than actual environmental risk. ${ }^{1}$

Environmental risks related to manufactured nanomaterials (MNMs) have been extensively discussed in the scientific literature since the middle of the 2000s. ${ }^{3-5}$ The main approach suggested for assessing such risks has been the type of environmental risk assessment commonly used for chemical substances. ${ }^{6,7}$ Indeed, progress has been made regarding the development of risk assessment methods for MNMs, for example in the form of the recently developed fate models MendNano, ${ }^{8}$ SimpleBox4nano, 9 and nanoFate. ${ }^{10}$ However, a number of studies question whether an accurate assessment of
MNM risks is possible, much in line with the idea about nature's intrinsic overcomplexity. ${ }^{1,2}$

While not questioning the theoretical possibility to assess environmental risks related to MNMs, Grieger et al. ${ }^{11}$ wrote that this "will quite possibly take decades even for those [manufactured] nanomaterials that are currently on the market, let alone those that are emerging." They also stated that even compared to other difficult-to-assess chemicals, such as endocrine disruptors, MNMs may be an "extreme case" and instead suggest a focus on approaches to facilitate near-term decisions. Syberg and Hansen ${ }^{12}$ questioned the ability of environmental risk assessments to provide a transparent and objective foundation for decision-making regarding MNMs by discussing a number of problems, such as the inability to determine particle characteristics during toxicity testing. They therefore recommend to also use other relevant decision-

Received: September 25, 2018

Revised: October 31, 2018

Accepted: November 13, 2018

Published: November 13, 2018 

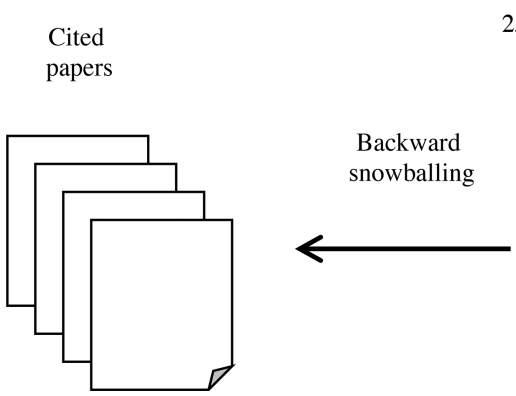

25 point-of-departure

review papers

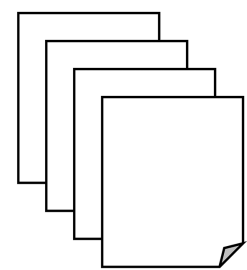

Citing

papers

Figure 1. Illustration of the review procedure followed.

making tools in combination with the application of the precautionary principle. Furthermore, Miller and Wickson ${ }^{13}$ even questioned the entire risk assessment approach as basis for regulation of emerging technologies in general and nanomaterials in particular, referring to risk assessment of MNMs as a "naked emperor". Problems highlighted include the lack of a MNM definition and the lack of measurement methods for MNMs. Again, a call was made for new approaches. In all three articles, concerns are thus raised regarding the adequacy of conventional environmental risks assessment approaches for assessing MNMs.

As alternatives or complements to conventional risk assessments, a number of screening risk assessment methods for MNMs have been developed, of which a few cover also environmental risks. ${ }^{14-17}$ However, these methods typically require $>10$ input parameters to be applicable, for which input data is not always easily available. For example, the NanoHAZ and Precautionary Matrix methods both require approximately 10 input parameters each for a complete environmental assessment, including parameters such as particle size, surface area, density, half-life, potential for release, and toxicity data. ${ }^{18,19}$ For proxy measures, on the other hand, the number of input parameters is set by the number of measures selected and can thus be as low as one, or two as in the original proposal by Scheringer and Berg, ${ }^{2}$ who suggested as indicators temporal duration (persistence) and the potential for large geographical distribution (spatial range).

The aim of this paper is to identify relevant proxy measures that can be used for simplified low-data screening environmental assessments of MNMs. A review of the literature on environmental risks of MNMs is conducted, resulting in an initial list of potential proxy measures. Their link to environmental risk and data availability are then critically discussed. Finally, two identified proxy measures deemed promising regarding links to environmental risk and data availability-production volume and aquatic ecotoxicity-are employed as proof of concept in a simplified assessment of seven MNMs.

\section{MATERIALS AND METHODS}

2.1. Review and Evaluation of Proxy Measures. Since the term proxy measure itself is rarely used in papers about MNMs and environmental risk, a more indirect approach than simply searching for this specific term was employed. We departed from a nonexhaustive initial corpus of 25 review-type papers (listed in Supporting Information (SI) Table S1). These papers were selected to cover different aspects of MNM risks: environmental release, fate, ecotoxicity, and risk in general. In addition to these, we followed potentially interesting studies cited in the papers and studies citing the papers in a backward and forward snowballing manner, ${ }^{20}$ respectively (see Figure 1 for an illustration of the method). In these publications, we identified potential proxy measures and evaluated them according to a number of criteria. According to Berg and Scheringer, ${ }^{1}$ a proxy measure should be simple. In addition, a proxy measure should be applicable to "various human activities", which in this specific case could mean all MNMs and not only specific types. Following Scheringer and Berg, ${ }^{2}$ proxy measures are understood as quantifiable, typically belonging to the real numbers (i.e., $\epsilon \mathbb{R}$ ). A proxy measure should also reflect the potential for adverse effects in the future, thereby making it possible to take actions before effects are realized. ${ }^{1}$ It should thus have a strong link to environmental risk through plausible cause-effect chains. The potential proxy measures were furthermore evaluated based on data availability, which has generally been realized to be crucial for any indicator. $^{21,22}$ The evaluation criteria were thus that the measures should: (1) be simple, (2) be applicable to all MNMs, (3) be quantifiable, (4) have a strong link to environmental risk, and (5) have a decent data availability. Proxy measures satisfying criteria (1), (2), and (3) were selected in the review to be further evaluated. These measures were then discussed in more detail regarding the satisfying of (4) and (5), see Section 3.

\subsection{Proof of Concept with Production Volume and} Aquatic Ecotoxicity. The two identified proxy measures production volume and aquatic ecotoxicity qualified to all five evaluation criteria. As proof of concept, they were therefore applied to assess seven MNMs: titanium dioxide nanomaterials (nano- $\mathrm{TiO}_{2}$ ), cerium dioxide nanomaterials (nano- $\mathrm{CeO}_{2}$ ), zinc oxide nanomaterials (nano- $\mathrm{ZnO}$ ), carbon nanotubes (CNT), silver nanomaterials (nano-Ag), silicon dioxide nanomaterials (nano- $\mathrm{SiO}_{2}$ ), and graphene.

For production volume, the annual global production of nano- $\mathrm{TiO}_{2}$, nano- $\mathrm{CeO}_{2}$, nano- $\mathrm{ZnO}, \mathrm{CNT}$, nano-Ag, and nano$\mathrm{SiO}_{2}$ were obtained from the study by Piccinno et al. ${ }^{23}$ Although other sources of production volume data exist, ${ }^{24}$ this study was selected due to its transparent description of the data gathering through surveys with companies producing and using MNMs. The median values, 25th percentiles and 75th percentiles from this study were obtained for the six MNMs. The current global production of graphene has been estimated at roughly 2000 metric tonnes/year in a market report by a technology consultancy company. ${ }^{25}$

Data for aquatic ecotoxicity for nano- $\mathrm{TiO}_{2}$, nano- $\mathrm{CeO}_{2}$, nano- $\mathrm{ZnO}, \mathrm{CNT}$ and nano-Ag were collected from the NanoETox database. ${ }^{26}$ All available data for $50 \%$ effect, inhibition and lethal concentrations $\left(\mathrm{EC}_{50}, \mathrm{IC}_{50}\right.$ and $\mathrm{LC}_{50}$, respectively) were gathered for algal, crustacean, and fish tests for the five MNMs. These tests were chosen since they constitute the base set for 
short-term aquatic toxicity for environmental risk assessment. ${ }^{27}$ Values were recalculated into the unit of $\mathrm{mg} / \mathrm{L}$ if reported in other units. There were 66 values for nano- $\mathrm{TiO}_{2}$ (results of 17 algal, 45 crustacean, and 4 fish tests), 34 for nano- $\mathrm{CeO}_{2}(20$ algal and 14 crustacean tests), 36 for $\mathrm{ZnO}$ (2 algal, 31 crustacean, and 3 fish tests), 29 for CNT (13 algal and 16 crustacean tests), and 150 for nano-Ag ( 7 algal, 111 crustacean, and 32 fish tests). Nano- $\mathrm{SiO}_{2}$ is not included in the NanoE-tox database, so its $\mathrm{EC}_{50}, \mathrm{IC}_{50}$, and $\mathrm{LC}_{50}$ values were instead obtained from the review by Wang et al. ${ }^{28}$ In this way, eight values were obtained for nano- $\mathrm{SiO}_{2}$ ( 3 algal, 3 crustacean, and 2 fish tests). Graphene is not included in the NanoE-tox database either, but four $\mathrm{EC}_{50}$ and $\mathrm{IC}_{50}$ values for graphene from three studies were identified ( 2 algal, 2 crustacean tests). ${ }^{29-31}$ Median values, 25 th percentiles and 75 th percentiles were calculated and inverted so that higher values imply higher toxicity. All input data for the proof of concept are shown in Table 1.

\section{Table 1. Input Data for the Proof-of-Concept Illustration ${ }^{a}$}

$\begin{array}{lll}\begin{array}{c}\text { manufactured } \\ \text { nanomaterial }\end{array} & \begin{array}{c}\text { median production } \\ {[\text { metric tonnes/year }]}\end{array} & \begin{array}{c}\text { Median } 1 / \mathrm{EC}_{50}, 1 / \mathrm{LC}_{50}, 1 / \\ \mathrm{IC}_{50}[1 /(\mathrm{L} / \mathrm{mg})]\end{array} \\ \begin{array}{l}\text { nano- } \mathrm{TiO}_{2} \\ \text { nano- } \mathrm{CeO}_{2}\end{array} & 3000(550,5500) & 0.077(0.013,0.34) \\ \text { nano- } \mathrm{ZnO} & 550(55,550) & 0.10(0.059,0.25) \\ \mathrm{CNT} & 300(55,550) & 0.47(0.22,0.91) \\ \text { nano-Ag } & 55(5.5,550) & 0.079(0.044,0.13) \\ \text { nano-SiO } & 5500(55,55000) & 21(5.4,120) \\ & & 0.00011(0.000040, \\ \text { graphene } & 2000 & 0.00026) \\ \end{array}$

$a_{25 \text { th }}$ and 75 th percentiles are shown within parentheses if available. Note that the ecotoxicity values have been inverted so that higher values imply higher toxicity.

If proxy measures are to be used for regulatory purposes or similar, acceptability thresholds may be needed. For example, Scheringer ${ }^{32}$ proposed to differ between long- and shortranged chemicals based on their spatial range. Examples of threshold were therefore employed for production volume and aquatic ecotoxicity as proof of concept. Since 1000 metric tonnes/year is the threshold for the most extensive testing requirement in the European legislation on Registration, Evaluation and Authorization and restrictions of Chemicals $(\mathrm{REACH}),{ }^{27}$ implying the highest concern, it is employed as threshold for production volume in this study as well. Following the Classification, Labeling and Packaging (CLP) regulation's classification for acute aquatic toxicity (Acute 1), 1 $\mathrm{mg} / \mathrm{L}$ was set as threshold for aquatic ecotoxicity. These thresholds can furthermore be linked to appropriate action or monitoring. When high values exist for both MNM production volumes and aquatic ecotoxicity (i.e., above threshold), action in the form of regulation or voluntary initiatives should be undertaken. In the case of low production volume but high aquatic ecotoxicity, monitoring of the production volumes is recommended to ensure they stay below the threshold value. Similarly, when high production volumes but low aquatic ecotoxicity is found for MNMs, monitoring of the ecotoxicological literature is recommended to ensure that new findings are in line with the current ones (i.e., that the ecotoxicity is below the threshold). Finally, in the case of both low production volumes and low aquatic ecotoxicity, no immediate action is required, but the assessment can be revisited continuously to confirm the result.

\section{RESULTS AND DISCUSSION}

Eighteen potential proxy measures were identified from the reviewed literature. These are shown in Table 2 together with information on how they link to environmental risk. In Sections 3.1-3.5, the identified proxy measures are discussed in more detail regarding data availability and their link to environmental risk. Furthermore, the two proxy measures of production volume and aquatic ecotoxicity are applied as proof of concept and further discussed in Section 3.6.

A number of parameters available in the reviewed literature were not included in this study as potential proxy measures since they did not meet the three first criteria specified in Section 2.1. For example, risk characterization ratios (RCR), predicted environmental concentrations (PEC), and predicted no-effect concentrations (PNEC) where excluded due to lack of simplicity. They are all outputs from different steps in the conventional risk assessment framework for chemicals and rely on more or less complicated models that in turn need substantial input data. ${ }^{33}$ Other risk-relevant properties of MNMs, such as coatings and shape, ${ }^{34}$ cannot be easily quantified and were therefore also excluded from the list of potential proxy measures.

3.1. Socio-Technical Measures. Production and release of a MNM are obviously the origins of any environmental risks related to that MNM. Without production and release, there can be no exposure and thus there can be no environmental risk. In general, for a given time period, a fraction of the produced MNMs becomes released to the environment, whereas the rest remains in the technosphere. Mathematically, production volume $(P)$ and release $(R)$ between the times $t_{0}$ and $t_{1}$ are thus related according to

$$
\int_{t_{0}}^{t_{1}} R(t) \mathrm{d} t=x \int_{t_{0}}^{t_{1}} P(t) \mathrm{d} t
$$

where $x=[0,1]$ is often referred to as a release or emission factor.

For production volume, data for global and some regional production volumes of most major $\mathrm{MNMs}$ (e.g., nano- $\mathrm{TiO}_{2}$, nano- $\mathrm{ZnO}, \mathrm{CNT}$, and nano- $\mathrm{Ag}$ ) are available in the scientific literature $23,35,36$ and market reports. There also exist production volume estimations included as input data in environmental exposure and risk assessments of MNMs, see for example Gottschalk et al. ${ }^{37}$ and Wang et al. ${ }^{28}$ Estimating release is more challenging, but release estimates for different geographical regions also exist in the scientific literature for most major MNMs. ${ }^{38-43}$ Other studies provide release estimates for specific products, which can later be used in studies estimating the total release of a MNM. ${ }^{44-49}$ Consequently, both production volume and release have high potential as proxy measures due to their strong link to environmental risk and decent data availability.

3.2. Particle-Specific Measures. The particle-specific measures identified as potential proxy measures include particle size, two attachment efficiencies, the zeta potential, and the dissolution rate. The main rationale behind particle size as proxy measure is that smaller particle size results in a higher surface area, which in turn gives higher reactivity and therefore higher toxicity. ${ }^{50,51}$ In addition, particle size may also influence cellular uptake and environmental fate. ${ }^{52,53}$ This 
Table 2. List of Potential Proxy Measures for Manufactured Nanomaterials. A Strong Link Implies an Unambiguous Influence on Environmental Risk, Whereas a Weak Link Implies Ambiguous Influence

\begin{tabular}{|c|c|c|c|c|c|}
\hline proxy measures & common symbols & SI units & $\begin{array}{l}\text { link to environmental } \\
\text { risk }\end{array}$ & $\begin{array}{c}\text { data } \\
\text { availability }\end{array}$ & example reference \\
\hline \multicolumn{6}{|l|}{ Socio-Technical Measures } \\
\hline production volume & $P$ & $\mathrm{~kg} /$ year & strong & decent & Piccinno et al. ${ }^{23}$ \\
\hline release $^{a}$ & $R$ & $\mathrm{~kg} /$ year & strong & decent & Keller and Lazareva ${ }^{38}$ \\
\hline \multicolumn{6}{|l|}{ Particle-Specific Measures } \\
\hline particle size & $d$ & $\mathrm{~m}$ & weak & low & Nel et al. ${ }^{51}$ \\
\hline attachment efficiency & $\alpha_{\text {het-agg }}$ or $\alpha_{\text {hom-agg }}$ & & weak & low & Praetorius et al. ${ }^{68}$ \\
\hline surface affinity & $\alpha_{\mathrm{D}}$ & & weak & low & Westerhoff and Nowack ${ }^{64}$ \\
\hline dissolution rate & $k_{\text {diss }}$ & $\mathrm{s}^{-1}$ & weak & low & Quik et al. $^{69}$ \\
\hline zeta potential & $\zeta$ & $\mathrm{V}$ & weak & low & Handy et al. $^{71}$ \\
\hline \multicolumn{6}{|l|}{ Partitioning Measures } \\
\hline octanol-water coefficient & $K_{\text {ow }}$ & & weak & low & Hristovski et al. ${ }^{79}$ \\
\hline organic carbon-water coefficient & $K_{\mathrm{oc}}$ & & weak & low & Grieger et al. ${ }^{77}$ \\
\hline soil-liquid coefficient & $K_{\mathrm{D}}$ & $\mathrm{m}^{3} / \mathrm{kg}$ & weak & low & Westerhoff and Nowack ${ }^{64}$ \\
\hline \multicolumn{6}{|l|}{ Other Fate Measures } \\
\hline half-life & $t_{1 / 2}$ & $\mathrm{~s}$ & weak & low & Hansen et al. ${ }^{81}$ \\
\hline bioconcentration factor & $\mathrm{BCF}$ & & weak & low & Hansen et al. ${ }^{81}$ \\
\hline biomagnification factor & BMF & & strong & low & Hansen et al. ${ }^{81}$ \\
\hline density & $\rho$ & $\mathrm{kg} / \mathrm{m}^{3}$ & weak & high & Quik et al. ${ }^{34}$ \\
\hline \multicolumn{6}{|l|}{ Ecotoxicological Measures } \\
\hline $50 \%$ effect concentration (aquatic, terrestrial, etc.) & $\mathrm{EC}_{50}$ & $\mathrm{~kg} / \mathrm{m}^{3}$ & strong & decent & Kahru and Dubourguier ${ }^{65}$ \\
\hline $50 \%$ inhibition concentration (aquatic, terrestrial, etc.) & $\mathrm{IC}_{50}$ & $\mathrm{~kg} / \mathrm{m}^{3}$ & strong & decent & Juganson et al. ${ }^{26}$ \\
\hline $50 \%$ lethal concentration (aquatic, terrestrial, etc.) & $\mathrm{LC}_{50}$ & $\mathrm{~kg} / \mathrm{m}^{3}$ & strong & decent & Kahru and Dubourguier ${ }^{65}$ \\
\hline $\begin{array}{l}\text { no observable effect concentration (aquatic, terrestrial, } \\
\text { etc.) }\end{array}$ & NOEC & $\mathrm{kg} / \mathrm{m}^{3}$ & strong & decent & Kahru and Dubourguier ${ }^{65}$ \\
\hline
\end{tabular}

${ }^{a}$ Note that release can also be referred to as emission.

parameter relates to the very definition of MNMs. It is often suggested that a material must have at least one dimension in the $1-100 \mathrm{~nm}$ range in order to qualify as a nanomaterial. ${ }^{54}$ However, a review has shown that many other size ranges have also been suggested for defining nanomaterials, including less than $200 \mathrm{~nm}$, less than $300 \mathrm{~nm}$, less than $500 \mathrm{~nm}$, and less than $1000 \mathrm{~nm} .{ }^{55}$ Although particle size is often mentioned as a parameter of importance for MNM toxicity and fate, the exact causality between the parameter and environmental risk is unclear. Some studies point at a wider size range than 1-100 $\mathrm{nm}$ being of environmental interest. For example, the screening risk assessment method called the Precautionary Matrix differentiates between nanoparticles smaller than $500 \mathrm{~nm}$ and larger particles, where the former are assumed to be more hazardous to the environment. ${ }^{18}$ Wardak et al. ${ }^{56}$ instead used a limit of less than $200 \mathrm{~nm}$ for the same purpose. In addition, Maynard et al. ${ }^{57}$ wrote that "there is little reason not to suppose that some materials may exhibit abrupt changes in behavior above $100 \mathrm{~nm}$ ". Other studies suggest that a narrower size range than $1-100 \mathrm{~nm}$ should be in focus from an environmental point of view. Bai et al. ${ }^{58}$ state that although there seems to exist particle size threshold levels for environmentally relevant physio-chemical properties of MNMs, these thresholds are often below $100 \mathrm{~nm}$. More specifically, Auffan et al. ${ }^{59}$ observed that inorganic particles larger than $30 \mathrm{~nm}$ typically do not show physio-chemical properties that imply different environmental effects than their bulk material counterparts. These conflicting views on which sizes that lead to environmental risk limits its usefulness as a proxy measure. Regarding data availability, particle sizes vary between products and are typically only available for a limited number of MNM products from which release has been studied experimentally. ${ }^{60}$
The most frequently mentioned attachment efficiency is that between particles (sometimes referred to as collision efficiency), which tells the share of particle collisions leading to agglomeration on a scale from 0 (no particles agglomerate at collision) to 1 (all particles agglomerate at collision). It thus tells to which extent agglomeration occurs, which is an important fate process for MNMs. ${ }^{61,62}$ This attachment efficiency comes in two forms: the homoagglomeration attachment efficiency $\left(\alpha_{\text {hom-agg }}\right)$, which applies for collisions between particles of the same type, and the heteroagglomeration attachment efficiency $\left(\alpha_{\text {het-agg }}\right)$, which applies for collisions between different types of particles. ${ }^{63}$ Another type of attachment efficiency is the surface affinity, which tells the tendency of a particle to attach to surfaces in the environment, such as soil and sediment. ${ }^{64}$ The surface affinity also varies between 0 (no particles attach to a surface at collision) and 1 (all particles attach to a surface at collision). The exact causality between attachment efficiencies and ecotoxicity remains unclear since even highly agglomerated MNMs can cause toxic effects. ${ }^{53,65}$ Furthermore, attachment efficiencies can generally not be modeled accurately but need to be measured empirically for different conditions. ${ }^{66,67}$ A number of measurements of attachment efficiencies have been conducted, ${ }^{67}$ but only a few of those are for heteroagglomeration, ${ }^{68}$ which is more relevant from an environmental point of view. ${ }^{69}$ A general problem with attachment efficiencies is their dependence on environmental conditions, such as ion concentration, $\mathrm{pH}$, and the presence of natural organic matter. $^{70}$ This means that it is difficult to tell the general attachment efficiency of a certain MNM, since the efficiency is an emergent property dependent on both the particle and its physio-chemical-biological environment. The low data 
availability and the determination difficulty limits the relevance of attachment efficiencies as proxy measures.

The zeta potential can be described as a measure of the surface charge of particles ${ }^{71}$ and can be seen as a particle analog to the ionic charge of a molecule. It influences the agglomeration behavior: if the zeta potential is near zero, agglomeration between particles increases due to low electrostatic repulsion while the opposite is true when the zeta potential increases. $^{72}$ At the so-called point of zero charge, agglomeration can be particularly rapid. ${ }^{73}$ The zeta potential is also influenced by the $\mathrm{pH}$ of the surrounding medium and, in turn, influences the attachment efficiency. ${ }^{34}$ As such, it carries the same problems as the attachment efficiency regarding link to environmental risk and the difficulty of determining a general zeta potential for a certain MNM.

Dissolution, which is when particles dissolve into their constituting atoms or ions, can be seen as a particle analog to degradation. ${ }^{69}$ The parameter used to quantify the dissolution process is the dissolution rate constant. ${ }^{64}$ The dissolution rate constant has been employed in different fate models for MNMs to account for their varying persistence in different media. ${ }^{8,9,63}$ Dissolution rates have been measured for some major MNMs, such as nano- $\mathrm{TiO}_{2}$, nano- $\mathrm{CeO}_{2}$, nano- $\mathrm{ZnO}$, nano- $\mathrm{Ag}$, and nano- $\mathrm{SiO}_{2} .{ }^{69}$ However, similarly to the attachment efficiency, the dissolution rate constant is an emergent property influenced by a number of environmental factors, including ionic strength, $\mathrm{pH}$, and temperature. ${ }^{72,74}$ Determining a general dissolution rate constant of a MNM is therefore difficult. Another problem with the dissolution rate as proxy measure is that the dissolved atoms or ions can be more toxic than the MNM. ${ }^{72}$ For nano-Ag, for example, it seems that it is the dissolved ions that mainly cause toxicity. ${ }^{75}$ Whether a high or low dissolution rate of MNMs is beneficial from an environmental point of view thus seems to be unclear at the moment and could possibly vary between MNMs, thus disqualifying the dissolution rate as a useful proxy measure.

3.3. Partitioning Coefficients. Similar to the attachment efficiencies described in Section 3.2, partitioning coefficients are dimensionless ratios between two states. They generally follow the principle of the following equation, where $K_{i, \mathrm{AB}}$ is the partitioning coefficient for material $i, C_{i, A}$ the concentration in medium $\mathrm{A}$ and $C_{i, \mathrm{~B}}$ the concentration in medium $\mathrm{B}:{ }^{76}$

$$
K_{i, \mathrm{AB}}=C_{i, \mathrm{~A}} / C_{i, \mathrm{~B}}
$$

In the context of MNM risks, a number of different partitioning coefficients have been discussed: the octanolwater coefficient, the organic carbon-water coefficient, and the solid-liquid coefficient. ${ }^{64,77}$ The link to environmental risk for the octanol-water coefficient is that since biological organisms have organic membranes separating them from the surrounding environment, a high water-octanol coefficient is related to increased uptake. ${ }^{64}$ The organic carbon-water partitioning coefficient describes the ability of a substance to adsorb to organic carbon and thus move through carbon-rich environments, including living beings. ${ }^{77}$ The soil-liquid partitioning coefficient determines the partitioning of substances between solid and liquid phases, thereby predicting exposure to organisms in these two compartments. ${ }^{64}$ Note that the difference between the soil-water partitioning coefficient and the surface affinity (Section 3.2) is that the surface affinity determines the share of particles that becomes attached to the surface of, for example, soil, whereas the soil-water partitioning coefficient tells the ratio between the concentrations of a substance in soil and water, respectively.

Regarding the link to environmental risk, MNMs tend to accumulate just in the interface between octanol and water, thus making a measurement of the octanol-water coefficient difficult for MNMs. ${ }^{64}$ This behavior has raised questions about the usefulness of the octanol-water coefficient for predicting MNM fate. Praetorius et al. ${ }^{76}$ referred to the application of such coefficients for MNMs as a "road to nowhere" since particles in the environment tend to be thermodynamically unstable and thus never reach equilibrium partitioning. This means that the relative concentration between two media will always be a function of time for MNMs. On the contrary, Dale et al. $^{78}$ suggest that applying partitioning coefficients may be justified for large-scale fate models from a practical standpoint, potentially even making them less error-prone than models relying on attachment efficiencies. This dispute over the relevance of partitioning coefficients in environmental fate modeling of MNMs raises questions about their general relevance as proxy measures for MNMs. As a possible remedy, Hristovski et al. ${ }^{79}$ proposed a partitioning coefficient that also includes the interface between the aqueous and organic phases as an additional medium. They also recommended the use of mass instead of concentration as in the conventional octanolwater coefficient (eq 2). There exist a limited number of measurements of these partitioning coefficients for MNMs, rendering data availability low. ${ }^{79}$

3.4. Other Fate Measures. Half-life, bioconcentration factors (BCFs) and biomagnification factors (BMFs) are faterelated measures used in conventional chemical risk assessment and screening assessments of chemical risk. ${ }^{33,80}$ An example of their application is the classification of chemicals as persistent, bioaccumulating, and toxic (PBT) and very persistent and very bioaccumulating ( $\mathrm{vPvB})$. These parameters have also been suggested for use when assessing risks related to MNMs. ${ }^{81,82}$ In a paper about early warning signs for screening of harmful properties of MNMs, Hansen et al. ${ }^{82}$ suggest persistence as an early warning sign and assess it on a qualitative yes/no basis. In the screening risk assessment tool NanoRiskCat, both the halflife and BMF are employed to categorize MNMs as having high, medium, low or unknown effects to the environment. For the half-life, 40 days is employed as threshold, whereas 0.1 is employed as threshold levels for the BMF in NanoRiskCat. ${ }^{83}$ The rational for including the half-life is that the longer the MNM stays in the environment, the higher the exposure will be. Regarding the relevance of half-life as proxy measure, see the discussion about the dissolution rate in Section 3.2 since it constitutes a particle analog to the half-life. BCFs, in theory, also indicate higher potential exposure. However, $\mathrm{BCF}$ s have been considered invalid for MNMs since they can accumulate in organisms without reaching equilibrium between the organism and the surrounding medium, potentially reaching higher concentrations than the BCF would imply. ${ }^{84,85}$ The link between the $\mathrm{BCF}$ and environmental risk is therefore weak for MNMs. High BMFs also indicate the potential for high exposure, in particular to top predators in the food chain. For both half-lives and BMFs of MNMs, data is relatively limited, which restricts their applicability as proxy measures.

The density is a basic property of any material and has been suggested as relevant to MNM risk. For example, Quik et al. ${ }^{34}$ mention it as an intrinsic MNM property that could possibly be of value for deriving quantitative property-property relationships for MNMs. A number of authors note that the 


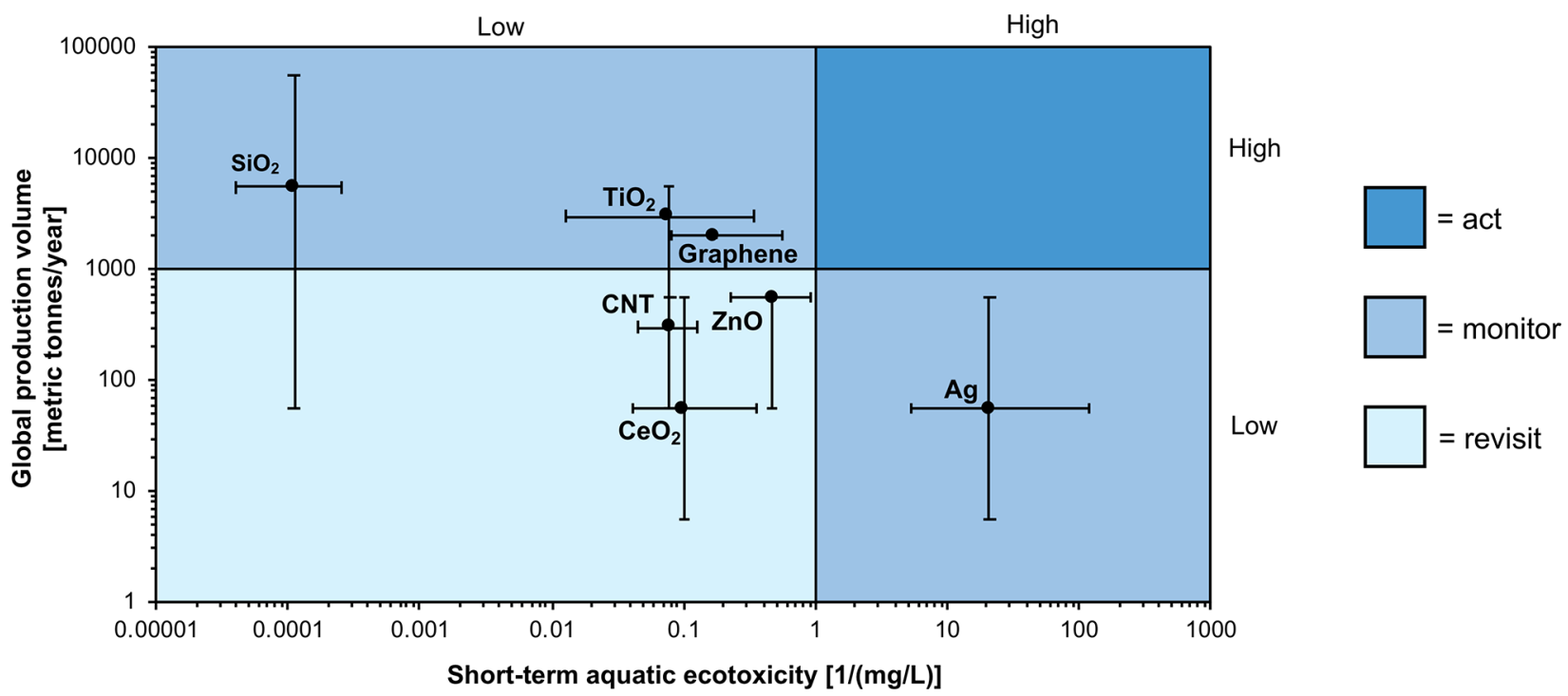

Figure 2. Proof of concept assessment of seven manufactured nanomaterials using the two proxy measures production volume and short-term aquatic ecotoxicity. Circles show median values and ranges show interval between the 25 th and 75 th percentile. Note that the ecotoxicity values have been inverted so that higher values imply higher ecotoxicity.

density influences agglomeration and sedimentation behavior toward higher removal. ${ }^{63,69,71,86}$ Considering the abundance of density data for bulk materials, which should in part be of relevance also to their MNM counterparts, data availability is regarded as high. Some specific measurements of densities also exist for MNMs that differ from their bulk material allotropes, such as CNT. ${ }^{87}$ However, whether a high density equals high risk is unclear, in particular since a higher removal from water means a higher inflow of MNMs to the sediment, thereby shifting risks between compartments.

3.5. Ecotoxicity Parameters. A higher aquatic, terrestrial or other type of ecotoxicity is logically related to a higher potential for environmental risk. Several parameters representing ecotoxicity can be found in the reviewed literature, with the $\mathrm{EC}_{50}, \mathrm{IC}_{50}, \mathrm{LC}_{50}$, and the no observable effect concentration (NOEC) being the most common. For a description of these parameters in general ecotoxicology, see, for example, Posthuma et al. ${ }^{88}$ A number of environmental risk assessment studies uses different types of ecotoxicity data as input to the effect assessment step, such as $\mathrm{EC}_{50}$ values, ${ }^{86,89} \mathrm{LC}_{50}$ values, ${ }^{86,89,90}$ and NOEC values. ${ }^{28,89-93} \mathrm{LC}_{50}$ is also used in the screening risk assessment tool NanoRiskCat. ${ }^{81}$ In general, a $50 \%$ value represent the most robust number that can be obtained from concentration-response experiments, why they are best suited candidates for proxy measures. However, the reliability of the available ecotoxicity data for MNMs have been questioned due to the difficulty of creating and maintaining stable MNM suspensions as well as poor characterization and test guidelines. ${ }^{85,94}$ Approaches to evaluate the reliability and relevance of MNM ecotoxicity data are available, such as the nanoCRED framework, ${ }^{95}$ allowing for an improvement of ecotoxicity as a proxy measure with respect to its link to environmental risk. Data availability for ecotoxicity of MNMs has increased over the last years. Whereas early reviews of MNM ecotoxicity contained $\sim 10$ studies $^{96}$ and $\sim 80$ ecotoxicity values, ${ }^{65}$ the recently developed NanoE-Tox database contains 224 studies and 1518 ecotoxicity values. ${ }^{26}$ These values cover most major MNMs. Data availability is therefore regarded as relatively high for ecotoxicity, indicating its feasability as a proxy measure.
3.6. Proof-of-Concept Results for Production Volume and Aquatic Ecotoxicity. Figure 2 illustrates the two proxy measures production volume and (reciprocal) short-term aquatic ecotoxicity applied to nano- $\mathrm{TiO}_{2}$, nano- $\mathrm{CeO}_{2}$, nano$\mathrm{ZnO}, \mathrm{CNT}$, nano-Ag, nano-SiO${ }_{2}$, and graphene. Given the exemplification with thresholds at 1000 metric tonnes/year and $1 \mathrm{mg} / \mathrm{L}$, none of the seven investigated MNMs end up in the high toxicity-high production quadrant. Nano-Ag ends up in the high ecotoxicity-low production volume quadrant. Whereas some authors have expressed concern over potentially high production volumes of nano- $\mathrm{Ag},{ }^{39}$ high ecotoxicity rather than high production seems to be the most imminent environmental issue for nano-Ag according to Figure 2. Continuous monitoring and improvement of data regarding production volumes of nano-Ag should be conducted to confirm that this result holds true also in the future. Graphene, nano- $\mathrm{TiO}_{2}$ and nano- $\mathrm{SiO}_{2}$ end up in the low ecotoxicity-high production volume quadrant. Consequently, immediate action is not warranted, but the scientific literature should be monitored to ensure that new ecotoxicological studies do not show higher ecotoxicity than the present ones. Three MNMs end up in the low ecotoxicity-low production volume quadrant: nano- $\mathrm{CeO}_{2}$, nano- $\mathrm{ZnO}$, and CNT. For these MNMs, it is recommended that the data on production volumes and ecotoxicity is revisited at regular intervals to confirm that new data do not alter the current evaluation.

The results in Figure 2 are broadly in line with those of more detailed environmental risk assessments conducted for MNMs, which generally show that most major MNMs are of low environmental concern as expressed by, for example, low $\mathrm{RCR},{ }^{97}$ in particular for CNT and nano- $\mathrm{SiO}_{2} \cdot{ }^{98}$ For example, Wang et al. ${ }^{28}$ showed that both the mean and median RCR for nano- $\mathrm{SiO}_{2}$ in the surface waters of Switzerland and the European Union (EU) were well below 0.01, whereas only values above 1 would imply risk. Coll et al. ${ }^{91}$ calculated RCR (mode values) less than 0.1 for nano- $\mathrm{TiO}_{2}$, nano-Ag, nano$\mathrm{ZnO}$ and $\mathrm{CNT}$ for the freshwaters, sludge-treated soils, and sediments of the EU. RCR for Danish surface waters calculated by Kjølholt et al., ${ }^{99}$ based on probabilistic PEC estimations and PNEC derived from quality-assessed ecotoxicity data, were 
even lower $(\leq 0.001)$ for nano- $\mathrm{TiO}_{2}$ (photostable and photocatalytic), nano- $\mathrm{ZnO}$, nano- $\mathrm{Ag}, \mathrm{CNT}$, and nano- $\mathrm{CeO}_{2}$. Considering relative rather than absolute toxicity impacts, Eckelman et al. ${ }^{100}$ calculated that under a realistic release scenario, toxicity impacts from release of CNT are exceeded at 3 orders of magnitude by other emissions during the life cycle production of CNT, mainly emissions of metals in electricity production. These results indicate that $\mathrm{CNT}$ is less of a concern compared to non-MNM contaminants. This general accordance with more detailed environmental assessments indicates the ability of the tested proxy measures to provide reasonable results. The ranges in Figure 2 illustrate a considerable uncertainty related to estimations of production volume and ecotoxicity of the seven MNMs, spanning orders of magnitude. The result for graphene is considered particularly uncertain due to the low availability of data, in particular on its production volume. However, despite these uncertainties, there are relatively few transgressions over the threshold levels set, which means that the overall result is quite robust even with such wide ranges.

\section{IMPLICATIONS FOR ENVIRONMENTAL ASSESSMENT OF MNMS}

The result in Figure 2 is only one example of the applicability of two proxy measures to seven MNMs with two threshold values. Multiple alternative applications are possible. While a global perspective is employed in Figure 2, the geographical boundary can be altered to fit the purpose of a risk screening for a specific region or regulatory body. For example, specific MNM production data exists for the United States, ${ }^{36}$ Denmark $^{101}$ and Switzerland. ${ }^{102}$ The resolution can also be altered regarding the type of MNMs assessed. In Figure 2, groups of MNMs, such as various types of CNT and nano$\mathrm{TiO}_{2}$, are assessed as single MNMs. A higher resolution can be obtained by instead assessing, for example, single-walled CNT and multiwalled $\mathrm{CNT}$, or nano- $\mathrm{TiO}_{2}$ from anatase and nano$\mathrm{TiO}_{2}$ from rutile, separately. MNMs with specific coatings and other surface modifications can also be considered separately if relevant and if data are available. It would also be possible to use other statistical metrics than median values, 25 th and 75 th percentiles, potential alternatives being for example mean, lowest and highest values. The threshold values for low/high production volume and ecotoxicity can also be altered, where lower thresholds imply more precaution. For example, 10 and $100 \mathrm{mg} / \mathrm{L}$, rather than $1 \mathrm{mg} / \mathrm{L}$, are used as threshold values in the NanoRiskCat tool to assign environmental hazard codes to MNMs. ${ }^{81}$ It can be noted that if a threshold value of $10 \mathrm{mg} / \mathrm{L}$ was applied for ecotoxicty (i.e., a value of $0.1 \mathrm{~L} / \mathrm{mg}$ in Figure $2)$, the materials graphene, $\mathrm{CeO}_{2}$, and $\mathrm{ZnO}$ would be considered more risky than in the current evaluation. Over time, MNM ecotoxicity data availability is expected to increase and production volumes to change, most likely increase ${ }^{35}$ unless regulatory restrictions measures are enforced. ${ }^{103}$ The assessment conducted here would thus need to be repeated regularly, for example, on an annual basis, with the most recent data to remain up to date.

In the example, two proxy measures are chosen, but it is also possible to choose a larger set from Table 2 in order to cover additional aspects of MNM risks. MNM release is a possible alternative to production volume since it also has a strong link to environmental risk and decent data availability. The BMF also has a strong link to environmental risk but currently low data availability and may thus become relevant to include as more data become available. For other proxy measures, the link to environmental risk may become revealed over time due to more research. There is furthermore an ongoing discussion about which metric is most appropriate to use in assessments of MNMs. Some authors argue that in addition to mass, which is used in most of the reviewed studies, particle number and surface area can be used. ${ }^{50,61}$ If found relevant and if data is available, proxy measures can be based on such metrics instead.

Clearly, no set of proxy measures, including the proof of concept provided in this study, captures all relevant aspects of the environmental risk of MNMs. However, proxy measures constitute a third approach that complements conventional and screening environmental risk assessments. Although the writings about nature's overcomplexity and indeterminism by Berg and Scheringer ${ }^{1}$ and Scheringer and Berg $^{2}$ seem to suggest that proxy measures are generally superior to conventional environmental risk assessments, we make the less controversial claim that proxy measures can be useful, in particular at early stages of technology development and diffusion. The main benefits with proxy measures are their low data requirement and the lack of complex assessment models, reflecting the view that the overcomplexity of the natural environment renders the predictive power of such models limited. ${ }^{1}$ Proxy measures are thus particularly appealing for assessing novel entities such as MNMs; in particular, novel MNMs for which data is particularly scarce. Early assessment results provided by proxy measures can give indications about environmental risk, thereby enabling a prioritization regarding which novel MNMs to study further in more detailed environmental assessments. The relationship between proxy measures and the two other approaches currently in use for environmental risk assessment of MNMs-conventional and screening risk assessments-can thus be a sequential one, where MNMs of high concern as assessed by proxy measures are studied further in conventional and screening risk assessments. Such a sequential approach can prevent the lack of risk governance and environmental management due to the inability to conduct other types of environmental risk assessments, thereby possibly avoiding a situation where regulatory decisions and actions related to MNMs are never taken ("paralysis by analysis"). ${ }^{104}$ Proxy measures can thus be part of more tiered, iterative and continuous approaches to risk governance of MNMs, such as reflexive innovation ${ }^{105}$ and risk management. ${ }^{106}$ The application of proxy measures in such a context can be conducted by regulatory bodies to prioritize their efforts in terms of when to fund and/or demand further testing to generate information needed, as well as when to initiate stakeholder deliberation about whether to implement regulatory restrictions of MNMs. Proxy measures can also be applied by proactive companies as part of self-regulatory efforts in their core activities or through their supply chains before regulation in terms of "hard laws" has been implemented. ${ }^{106} \mathrm{~A}$ set of well-selected proxy measures could then guide their research, development and investments. It should in this context be noted that in the very early technological development of novel MNMs, production volume as applied in this study's proof of concept would not be a suitable proxy measure, since at that point every MNM would get a low result. Instead, some projection or "what-if scenario" for future production volume would need to be applied, or possibly other proxy measures.

A potential benefit of early assessments using proxy measures is not only to avoid "paralysis by analysis" in terms 
of not implementing precautionary regulation when needed to protect human health and the environment, but also in terms of avoiding the delay of important technological innovations that could benefit both the environment and human health. Proxy measures can thus be used both as early condemning but also exonerating evidence. One example of such potentially beneficial technology is the research on MNM use in medical applications, including drug delivery, vaccine development, disinfection, diagnostics, implants and imaging. ${ }^{107}$ Another example is water treatment through nanoenabled membranes, or through pollutant removal and pathogen inactivation by nanoparticles. ${ }^{97,108}$ Functionalized fullerenes are furthermore used in organic solar cells, ${ }^{109}$ which have been shown to have impressive energy pay-back times in the order of days. ${ }^{110}$ This illustrates the importance of being able to tell at an early stage that a certain MNM- at least preliminary-seems to pose low environmental threat and proxy measures seem to be a feasible approach for such evaluations.

\section{ASSOCIATED CONTENT}

\section{S Supporting Information}

The Supporting Information is available free of charge on the ACS Publications website at DOI: 10.1021/acs.est.8b05405.

Table S1: The 25 point-of-departure review-type papers for the literature review (PDF)

\section{AUTHOR INFORMATION}

\section{Corresponding Author}

*Phone: +46 (0) 31772 2161; e-mail: rickard.arvidsson@ chalmers.se.

\section{ORCID *}

Rickard Arvidsson: 0000-0002-9258-0641

Anna Furberg: 0000-0001-9873-0949

\section{Notes}

The authors declare no competing financial interest.

\section{ACKNOWLEDGMENTS}

The financial support from the research program Mistra Environmental Nanosafety is gratefully acknowledged. R.A. gratefully acknowledges the financial support from the Swedish Research Council Formas. We furthermore thank two anonymous reviewers for their valuable comments.

\section{REFERENCES}

(1) Berg, M.; Scheringer, M. Problems in environmental risk assessment and the need for proxy measures. Fresen Environ. Bull. 1994, 3 (8), 487-492.

(2) Scheringer, M.; Berg, M. Spatial and temporal range as measures of environmental threat. Fresen Environ. Bull. 1994, 3 (8), 493-498.

(3) Colvin, V. L. The potential environmental impact of engineered nanomaterials. Nat. Biotechnol. 2003, 21 (10), 1166-1170.

(4) Nanoscience and Nanotechnologies: Opportunities and Uncertainties; Royal Society and Royal Academy of Engineering: London, 2004.

(5) Wiesner, M. R.; Lowry, G. V.; Alvarez, P.; Dionysiou, D.; Biswas, P. Assessing the risks of manufactured nanomaterials. Environ. Sci. Technol. 2006, 40 (14), 4336-4345.

(6) Scheringer, M. Nanoecotoxicology: Environmental risks of nanomaterials. Nat. Nanotechnol. 2008, 3 (6), 322-323.

(7) Koelmans, A. A.; Diepens, N. J.; Velzeboer, I.; Besseling, E.; Quik, J. T. K.; van de Meent, D. Guidance for the prognostic risk assessment of nanomaterials in aquatic ecosystems. Sci. Total Environ. 2015, 535, 141-149.
(8) Liu, H. H.; Cohen, Y. Multimedia Environmental Distribution of Engineered Nanomaterials. Environ. Sci. Technol. 2014, 48 (6), 32813292.

(9) Meesters, J. A. J.; Koelmans, A. A.; Quik, J. T. K.; Hendriks, A. J.; van de Meent, D. Multimedia Modeling of Engineered Nanoparticles with SimpleBox4nano: Model Definition and Evaluation. Environ. Sci. Technol. 2014, 48 (10), 5726-5736.

(10) Garner, K. L.; Suh, S.; Keller, A. A. Assessing the Risk of Engineered Nanomaterials in the Environment: Development and Application of the nanoFate Model. Environ. Sci. Technol. 2017, 51 (10), 5541-5551.

(11) Grieger, K.; Baun, A.; Owen, R. Redefining risk research priorities for nanomaterials. J. Nanopart. Res. 2010, 12 (2), 383-392.

(12) Syberg, K.; Hansen, S. F. Environmental risk assessment of chemicals and nanomaterials - The best foundation for regulatory decision-making? Sci. Total Environ. 2016, 541, 784-794.

(13) Miller, G.; Wickson, F. Risk Analysis of Nanomaterials: Exposing Nanotechnology's Naked Emperor. Rev. Policy Res. 2015, 32 (4), 485-512.

(14) Arvidsson, R.; Furberg, A.; Molander, S. Review of Screening Risk Assessment Methods for Nanomaterials; Chalmers University of Technology: Gothenburg, 2016.

(15) Erbis, S.; Ok, Z.; Isaacs, J. A.; Benneyan, J. C.; Kamarthi, S. Review of Research Trends and Methods in Nano Environmental, Health, and Safety Risk Analysis. Risk Anal 2016, 36 (8), 1644-1665.

(16) Grieger, K. D.; Linkov, I.; Hansen, S. F.; Baun, A. Environmental risk analysis for nanomaterials: Review and evaluation of frameworks. Nanotoxicology 2012, 6 (2), 196-212.

(17) Hristozov, D.; Gottardo, S.; Semenzin, E.; Oomen, A.; Bos, P.; Peijnenburg, W.; van Tongeren, M.; Nowack, B.; Hunt, N.; Brunelli, A.; Scott-Fordsmand, J. J.; Tran, L.; Marcomini, A. Frameworks and tools for risk assessment of manufactured nanomaterials. Environ. Int. 2016, 95, 36-53.

(18) Höck, J.; Hofmann, H.; Krug, H.; Lorenz, C.; Limbach, L.; Nowack, B.; Riediker, M.; Schirmer, K.; Som, C.; Stark, W.; Studer, C.; von Götz, N.; Wengert, S.; Wick, P. Guidelines on the Precautionary Matrix for Synthetic Nanomaterials, Version 1.1; Federal Office for Public Health and Federal Office for the Environment: Berne, 2008.

(19) O’Brien, N. J.; Cummins, E. J. Ranking initial environmental and human health risk resulting from environmentally relevant nanomaterials. J. Environ. Sci. Health, Part A: Toxic/Hazard. Subst. Environ. Eng. 2010, 45 (8), 992-1007.

(20) Wohlin, C., Guidelines for Snowballing in Systematic Literature Studies and a Replication in Software Engineering. In Proceedings of the 18th International Conference on Evaluation and Assessment in Software Engineering, 2014; pp 321-330.

(21) Meadows, D. Indicators and Information Systems for Sustainable Development - A Report to the Balaton Group; The Sustainablility Institute: Hartland Four Corners, 1998.

(22) Gallopín, G. C. Environmental and sustainability indicators and the concept of situational indicators. A systems approach. Environ. Model Assess 1996, 1 (3), 101-117.

(23) Piccinno, F.; Gottschalk, F.; Seeger, S.; Nowack, B. Industrial production quantities and uses of ten engineered nanomaterials in Europe and the world. J. Nanopart. Res. 2012, 14 (9), 1109.

(24) Furberg, A.; Arvidsson, R.; Molander, S., Very small flows? Review of the societal metabolism of nanomaterials. In Advances in Nanotechnology; Nova Science Publishers: Hauppauge, 2016; Vol. 15.

(25) Future Markets, I. Graphene; The Global Market.: Edinburgh, 2014.

(26) Juganson, K.; Ivask, A.; Blinova, I.; Mortimer, M.; Kahru, A. NanoE-Tox: New and in-depth database concerning ecotoxicity of nanomaterials. Beilstein J. Nanotechnol. 2015, 6, 1788-1804.

(27) Guidance on Information Requirements and Chemical Safety Assessment. Part B: Hazard Assessment; European Chemicals Agency: Helsinki, 2011.

(28) Wang, Y.; Kalinina, A.; Sun, T.; Nowack, B. Probabilistic modeling of the flows and environmental risks of nano-silica. Sci. Total Environ. 2016, 545-546, 67-76. 
(29) Pretti, C.; Oliva, M.; Pietro, R. D.; Monni, G.; Cevasco, G.; Chiellini, F.; Pomelli, C.; Chiappe, C. Ecotoxicity of pristine graphene to marine organisms. Ecotoxicol. Environ. Saf. 2014, 101, 138-145.

(30) Lu, K.; Huang, Q.; Wang, P.; Mao, L. Physicochemical Changes of Few-Layer Graphene in Peroxidase-Catalyzed Reactions: Characterization and Potential Ecological Effects. Environ. Sci. Technol. 2015, 49 (14), 8558-8565.

(31) Sanchís, J.; Olmos, M.; Vincent, P.; Farré, M.; Barceló, D. New Insights on the Influence of Organic Co-Contaminants on the Aquatic Toxicology of Carbon Nanomaterials. Environ. Sci. Technol. 2016, 50 (2), 961-969.

(32) Scheringer, M. Persistence and Spatial Range as Endpoints of an Exposure-Based Assessment of Organic Chemicals. Environ. Sci. Technol. 1996, 30 (5), 1652-1659.

(33) van Leeuwen, C. J.; Vermeire, T. G. Risk Assessment of Chemicals: An Introduction,2nd ed.; Springer: Dordrecht, 2007.

(34) Quik, J. T. K.; Bakker, M.; van de Meent, D.; Poikkimäki, M.; Dal Maso, M.; Peijnenburg, W. Directions in QPPR development to complement the predictive models used in risk assessment of nanomaterials. NanoImpact 2018, 11, 58-66.

(35) Robichaud, C. O.; Uyar, A. E.; Darby, M. R.; Zucker, L. G.; Wiesner, M. R. Estimates of Upper Bounds and Trends in Nano-TiO2 Production As a Basis for Exposure Assessment. Environ. Sci. Technol. 2009, 43 (12), 4227-4233.

(36) Hendren, C. O.; Mesnard, X.; Dröge, J.; Wiesner, M. R. Estimating Production Data for Five Engineered Nanomaterials As a Basis for Exposure Assessment. Environ. Sci. Technol. 2011, 45 (7), $2562-2569$.

(37) Gottschalk, F.; Sonderer, T.; Scholz, R. W.; Nowack, B. Modeled Environmental Concentrations of Engineered Nanomaterials ( $\mathrm{TiO} 2, \mathrm{ZnO}, \mathrm{Ag}, \mathrm{CNT}$, Fullerenes) for Different Regions. Environ. Sci. Technol. 2009, 43 (24), 9216-9222.

(38) Keller, A. A.; Lazareva, A. Predicted Releases of Engineered Nanomaterials: From Global to Regional to Local. Environ. Sci. Technol. Lett. 2014, 1 (1), 65-70.

(39) Arvidsson, R.; Molander, S.; Sandén, B. A. Impacts of a SilverCoated Future: Particle Flow Analysis of Silver Nanoparticles. J. Ind. Ecol. 2011, 15 (6), 844-854.

(40) Arvidsson, R.; Molander, S.; Sandén, B. A. Particle flow analysis - Exploring potential use phase emissions of $\mathrm{TiO} 2$ nanoparticles from sunscreen, paint and cement. J. Ind. Ecol. 2012, 16 (3), 343-351.

(41) Sun, T. Y.; Gottschalk, F.; Hungerbühler, K.; Nowack, B. Comprehensive probabilistic modelling of environmental emissions of engineered nanomaterials. Environ. Pollut. 2014, 185, 69-76.

(42) Sun, T. Y.; Bornhöft, N. A.; Hungerbühler, K.; Nowack, B. Dynamic Probabilistic Modeling of Environmental Emissions of Engineered Nanomaterials. Environ. Sci. Technol. 2016, 50 (9), 47014711.

(43) Keller, A. A.; McFerran, S.; Lazareva, A.; Suh, S. Global life cycle releases of engineered nanomaterials. J. Nanopart. Res. 2013, 15 (6), 1692.

(44) Al-Kattan, A.; Wichser, A.; Zuin, S.; Arroyo, Y.; Golanski, L.; Ulrich, A.; Nowack, B. Behavior of TiO2 Released from Nano-TiO2Containing Paint and Comparison to Pristine Nano-TiO2. Environ. Sci. Technol. 2014, 48 (12), 6710-6718.

(45) Kaegi, R.; Ulrich, A.; Sinnet, B.; Vonbank, R.; Wichser, A.; Zuleeg, S.; Simmler, H.; Brunner, S.; Vonmont, H.; Burkhardt, M.; Boller, M. Synthetic $\mathrm{TiO} 2$ nanoparticle emission from exterior facades into the aquatic environment. Environ. Pollut. 2008, 156 (2), 233239.

(46) Shandilya, N.; Le Bihan, O.; Bressot, C.; Morgeneyer, M. Emission of Titanium Dioxide Nanoparticles from Building Materials to the Environment by Wear and Weather. Environ. Sci. Technol. 2015, 49 (4), 2163-2170.

(47) Kaegi, R.; Sinnet, B.; Zuleeg, S.; Hagendorfer, H.; Mueller, E.; Vonbank, R.; Boller, M.; Burkhardt, M. Release of silver nanoparticles from outdoor facades. Environ. Pollut. 2010, 158 (9), 2900-2905.
(48) Geranio, L.; Heuberger, M.; Nowack, B. The Behavior of Silver Nanotextiles during Washing. Environ. Sci. Technol. 2009, 43 (21), 8113-8118.

(49) Benn, T. M.; Westerhoff, P. Nanoparticle Silver Released into Water from Commercially Available Sock Fabrics. Environ. Sci. Technol. 2008, 42 (18), 7025-7026.

(50) Dhawan, A.; Sharma, V.; Parmar, D. Nanomaterials: A challenge for toxicologists. Nanotoxicology 2009, 3 (1), 1-9.

(51) Nel, A.; Xia, T.; Madler, L.; Li, N. Toxic Potential of Materials at the Nanolevel. Science 2006, 311 (5761), 622-627.

(52) Nel, A. E.; Madler, L.; Velegol, D.; Xia, T.; Hoek, E. M. V.; Somasundaran, P.; Klaessig, F.; Castranova, V.; Thompson, M. Understanding biophysicochemical interactions at the nano-bio interface. Nat. Mater. 2009, 8 (7), 543-557.

(53) Klaine, S. J.; Alvarez, P. J. J.; Batley, G. E.; Fernandes, T. F.; Handy, R. D.; Lyon, D. Y.; Mahendra, S.; McLaughlin, M. J.; Lead, J. R. Nanomaterials in the Environment: Behaviour, Fate, Bioavailability, and Effects. Environ. Toxicol. Chem. 2008, 27 (9), 1825-1851.

(54) ISO Nanotechnologies-Terminology and Definitions for NanoObjects-Nanoparticle, Nanofibre and Nanoplate, ISO/TS 27687:2008(E), 2008.

(55) Boholm, M.; Arvidsson, R. A Definition Framework for the Terms Nanomaterial and Nanoparticle. NanoEthics 2016, 10 (1), 2540.

(56) Wardak, A.; Gorman, M. E.; Swami, N.; Deshpande, S. Identification of Risks in the Life Cycle of Nanotechnology-Based Products. J. Ind. Ecol. 2008, 12 (3), 435-448.

(57) Maynard, A. D.; Warheit, D. B.; Philbert, M. A. The New Toxicology of Sophisticated Materials: Nanotoxicology and Beyond. Toxicol. Sci. 2011, 120 (suppl 1), S109-S129.

(58) Bai, Y.; Wu, F.; White, J. C.; Xing, B. 100 Nanometers: A Potentially Inappropriate Threshold for Environmental and Ecological Effects of Nanoparticles. Environ. Sci. Technol. 2014, 48 (6), 30983099.

(59) Auffan, M.; Rose, J.; Bottero, J.-Y.; Lowry, G. V.; Jolivet, J.-P.; Wiesner, M. R. Towards a definition of inorganic nanoparticles from an environmental, health and safety perspective. Nat. Nanotechnol. 2009, 4 (10), 634-641.

(60) Caballero-Guzman, A.; Nowack, B. A critical review of engineered nanomaterial release data: Are current data useful for material flow modeling? Environ. Pollut. 2016, 213, 502-517.

(61) Arvidsson, R.; Molander, S.; Sandén, B. A.; Hassellöv, M. Challenges in Exposure Modeling of Nanoparticles in Aquatic Environments. Hum. Ecol. Risk Assess. 2011, 17 (1), 245-262.

(62) Dale, A. L.; Casman, E. A.; Lowry, G. V.; Lead, J. R.; Viparelli, E.; Baalousha, M. Modeling Nanomaterial Environmental Fate in Aquatic Systems. Environ. Sci. Technol. 2015, 49 (5), 2587-2593.

(63) Praetorius, A.; Scheringer, M.; Hungerbühler, K. Development of Environmental Fate Models for Engineered Nanoparticles-A Case Study of TiO2 Nanoparticles in the Rhine River. Environ. Sci. Technol. 2012, 46 (12), 6705-6713.

(64) Westerhoff, P.; Nowack, B. Searching for Global Descriptors of Engineered Nanomaterial Fate and Transport in the Environment. Acc. Chem. Res. 2013, 46 (3), 844-853.

(65) Kahru, A.; Dubourguier, H. C. From ecotoxicology to nanoecotoxicology. Toxicology 2010, 269 (2-3), 105-119.

(66) Wiesner, M. R. Kinetics of aggregate formation in rapid mix. Water Res. 1992, 26 (3), 379-387.

(67) Petosa, A. R.; Jaisi, D. P.; Quevedo, I. R.; Elimelech, M.; Tufenkji, N. Aggregation and Deposition of Engineered Nanomaterials in Aquatic Environments: Role of Physicochemical Interactions. Environ. Sci. Technol. 2010, 44 (17), 6532-6549.

(68) Praetorius, A.; Labille, J.; Scheringer, M.; Thill, A.; Hungerbühler, K.; Bottero, J.-Y. Heteroaggregation of Titanium Dioxide Nanoparticles with Model Natural Colloids under Environmentally Relevant Conditions. Environ. Sci. Technol. 2014, 48 (18), 10690-10698. 
(69) Quik, J. T. K.; Vonk, J. A.; Hansen, S. F.; Baun, A.; Van De Meent, D. How to assess exposure of aquatic organisms to manufactured nanoparticles? Environ. Int. 2011, 37 (6), 1068-1077.

(70) Baalousha, M.; Manciulea, A.; Cumberland, S.; Kendall, K.; Lead, J. Aggregation and Surface Properties of Iron Oxide Nanoparticles: Influence of $\mathrm{pH}$ and Natural Organic Matter. Environ. Toxicol. Chem. 2008, 27 (9), 1875-1882.

(71) Handy, R.; von der Kammer, F.; Lead, J.; Hassellöv, M.; Owen, R.; Crane, M. The ecotoxicology and chemistry of manufactured nanoparticles. Ecotoxicology 2008, 17 (4), 287-314.

(72) Garner, K. L.; Keller, A. A. Emerging patterns for engineered nanomaterials in the environment: a review of fate and toxicity studies. J. Nanopart. Res. 2014, 16 (8), 2503.

(73) Meesters, J. A. J.; Veltman, K.; Hendriks, A. J.; van de Meent, D. Environmental exposure assessment of engineered nanoparticles: Why REACH needs adjustment. Integr. Environ. Assess. Manage. 2013, 9 (3), e15-e26.

(74) Baun, A.; Sayre, P.; Steinhäuser, K. G.; Rose, J. Regulatory relevant and reliable methods and data for determining the environmental fate of manufactured nanomaterials. NanoImpact 2017, 8, 1-10.

(75) Lubick, N. Nanosilver toxicity: ions, nanoparticles-or both? Environ. Sci. Technol. 2008, 42 (23), 8617-8617.

(76) Praetorius, A.; Tufenkji, N.; Goss, K.-U.; Scheringer, M.; von der Kammer, F.; Elimelech, M. The road to nowhere: equilibrium partition coefficients for nanoparticles. Environ. Sci.: Nano 2014, 1 (4), 317-323.

(77) Grieger, K.; Redmon, J.; Money, E.; Widder, M.; van der Schalie, W.; Beaulieu, S.; Womack, D. A relative ranking approach for nano-enabled applications to improve risk-based decision making: a case study of Army materiel. Environ. Syst. Decis 2015, 35 (1), 42-53. (78) Dale, A. L.; Lowry, G. V.; Casman, E. A. Much ado about [small alpha]: reframing the debate over appropriate fate descriptors in nanoparticle environmental risk modeling. Environ. Sci.: Nano 2015, 2 (1), 27-32.

(79) Hristovski, K. D.; Westerhoff, P. K.; Posner, J. D. Octanol-water distribution of engineered nanomaterials. J. Environ. Sci. Health, Part A: Toxic/Hazard. Subst. Environ. Eng. 2011, 46 (6), 636-647.

(80) Swanson, M. B.; Socha, A. C. Chemical Ranking and Scoring: Guidelines for Relative Assessment of Chemicals; Society for Environmental Toxicology and Chemistry (SETAC) Press: Pansacola, 1997.

(81) Hansen, S. F.; Jensen Alstrup, K.; Baun, A. NanoRiskCat: a conceptual tool for categorization and communication of exposure potentials and hazards of nanomaterials in consumer products. $J$. Nanopart. Res. 2014, 16 (2195), 1-25.

(82) Hansen, S. F.; Nielsen, K. N.; Knudsen, N.; Grieger, K. D.; Baun, A. Operationalization and application of "early warning signs" to screen nanomaterials for harmful properties. Environ. Sci: Processes Impacts 2013, 15 (1), 190-203.

(83) Hansen, S. F.; Jensen, K. A.; Baun, A. Erratum to: NanoRiskCat: a conceptual tool for categorization and communication of exposure potentials and hazards of nanomaterials in consumer products. J. Nanopart. Res. 2017, 19 (7), 236.

(84) Skjolding, L. M.; Kern, K.; Hjorth, R.; Hartmann, N.; Overgaard, S.; Ma, G.; Veinot, J. G. C.; Baun, A. Uptake and depuration of gold nanoparticles in Daphnia magna. Ecotoxicology 2014, 23 (7), 1172-1183.

(85) Hjorth, R.; Skjolding, L. M.; Sørensen, S. N.; Baun, A. Regulatory adequacy of aquatic ecotoxicity testing of nanomaterials. NanoImpact 2017, 8, 28-37.

(86) Boxall, A. B. A.; Chaudhry, Q.; Sinclair, C.; Jones, A.; Aitken, R.; Jefferson, B.; Watts, C. Current and Future Predicted Environmental Exposure to Engineered Nanoparticles; Central Science Laboratory: York, 2007.

(87) Laurent, C.; Flahaut, E.; Peigney, A. The weight and density of carbon nanotubes versus the number of walls and diameter. Carbon 2010, 48 (10), 2994-2996.

(88) Posthuma, L.; Suter, G. W.; Traas, T. P. Species Sensitivity Distributions in Ecotoxicology; Lewis Publishers: Boca Raton, 2002.
(89) Musee, N. Simulated environmental risk estimation of engineered nanomaterials: A case of cosmetics in Johannesburg City. Hum. Exp. Toxicol. 2011, 30 (9), 1181-1195.

(90) Blaser, S. A.; Scheringer, M.; MacLeod, M.; Hungerbühler, K. Estimation of cumulative aquatic exposure and risk due to silver: Contribution of nano-functionalized plastics and textiles. Sci. Total Environ. 2008, 390 (2-3), 396-409.

(91) Coll, C.; Notter, D.; Gottschalk, F.; Sun, T.; Som, C.; Nowack, B. Probabilistic environmental risk assessment of five nanomaterials (nano-TiO2, nano-Ag, nano- $\mathrm{ZnO}, \mathrm{CNT}$, and fullerenes). Nanotoxicology 2016, 10 (4), 436-444.

(92) Gottschalk, F.; Kost, E.; Nowack, B. Engineered nanomaterials in water and soils: A risk quantification based on probabilistic exposure and effect modeling. Environ. Toxicol. Chem. 2013, 32 (6), $1278-1287$.

(93) Mueller, N. C.; Nowack, B. Exposure Modeling of Engineered Nanoparticles in the Environment. Environ. Sci. Technol. 2008, 42 (12), 4447-4453.

(94) Hansen, S. F.; Hjorth, R.; Skjolding, L. M.; Bowman, D. M.; Maynard, A.; Baun, A. A critical analysis of the environmental dossiers from the OECD sponsorship programme for the testing of manufactured nanomaterials. Environ. Sci.: Nano 2017, 4 (2), 282291.

(95) Hartmann, N. B.; Ågerstrand, M.; Lützhøft, H.-C. H.; Baun, A. NanoCRED: A transparent framework to assess the regulatory adequacy of ecotoxicity data for nanomaterials - Relevance and reliability revisited. NanoImpact 2017, 6, 81-89.

(96) Baun, A.; Hartmann, N.; Grieger, K.; Kusk, K. Ecotoxicity of engineered nanoparticles to aquatic invertebrates: A brief review and recommendations for future toxicity testing. Ecotoxicology 2008, 17 (5), 387-395.

(97) Mauter, M. S.; Zucker, I.; Perreault, F.; Werber, J. R.; Kim, J.$\mathrm{H}$.; Elimelech, M. The role of nanotechnology in tackling global water challenges. Nat. Sustainability 2018, 1 (4), 166-175.

(98) Arvidsson, R. Risk Assessments Show Engineered Nanomaterials To Be of Low Environmental Concern. Environ. Sci. Technol. 2018, 52 (5), 2436-2437.

(99) Kjølholt, J.; Gottschalk, F.; Brinch, A.; Lützhøft, H.-C. H.; Hartmann, N. B.; Nowack, B.; Baun, A. Environmental Assessment of Nanomaterial Use in Denmark; The Danish Environmental Protection Agency: Copenhagen, 2015.

(100) Eckelman, M. J.; Mauter, M. S.; Isaacs, J. A.; Elimelech, M. New Perspectives on Nanomaterial Aquatic Ecotoxicity: Production Impacts Exceed Direct Exposure Impacts for Carbon Nanotoubes. Environ. Sci. Technol. 2012, 46 (5), 2902-2910.

(101) Gottschalk, F.; Lassen, C.; Kjoelholt, J.; Christensen, F.; Nowack, B. Modeling Flows and Concentrations of Nine Engineered Nanomaterials in the Danish Environment. Int. J. Environ. Res. Public Health 2015, 12 (5), 5581-5602.

(102) Schmid, K.; Riediker, M. Use of Nanoparticles in Swiss Industry: A Targeted Survey. Environ. Sci. Technol. 2008, 42 (7), 2253-2260.

(103) Sun, T. Y.; Mitrano, D. M.; Bornhöft, N. A.; Scheringer, M.; Hungerbühler, K.; Nowack, B. Envisioning Nano Release Dynamics in a Changing World: Using Dynamic Probabilistic Modeling to Assess Future Environmental Emissions of Engineered Nanomaterials. Environ. Sci. Technol. 2017, 51 (5), 2854-2863.

(104) Hansen, S. F.; Baun, A. When enough is enough. Nat. Nanotechnol. 2012, 7 (7), 409-411.

(105) Fogelberg, H.; Sandén, B. A. Understanding reflexive systems of innovation: An analysis of Swedish nanotechnology discourse and organization. Technol. Anal Strateg Manage 2008, 20 (1), 65-81.

(106) Marchant, G. E.; Sylvester, D. J.; Abbott, K. W. Risk Management Principles for Nanotechnology. NanoEthics 2008, 2 (1), 43-60.

(107) Pelaz, B.; Alexiou, C.; Alvarez-Puebla, R. A.; Alves, F.; Andrews, A. M.; Ashraf, S.; Balogh, L. P.; Ballerini, L.; Bestetti, A.; Brendel, C.; Bosi, S.; Carril, M.; Chan, W. C. W.; Chen, C.; Chen, X.; Chen, X.; Cheng, Z.; Cui, D.; Du, J.; Dullin, C.; Escudero, A.; Feliu, 
N.; Gao, M.; George, M.; Gogotsi, Y.; Grünweller, A.; Gu, Z.; Halas, N. J.; Hampp, N.; Hartmann, R. K.; Hersam, M. C.; Hunziker, P.; Jian, J.; Jiang, X.; Jungebluth, P.; Kadhiresan, P.; Kataoka, K.; Khademhosseini, A.; Kopeček, J.; Kotov, N. A.; Krug, H. F.; Lee, D. S.; Lehr, C.-M.; Leong, K. W.; Liang, X.-J.; Ling Lim, M.; Liz-Marzán, L. M.; Ma, X.; Macchiarini, P.; Meng, H.; Möhwald, H.; Mulvaney, P.; Nel, A. E.; Nie, S.; Nordlander, P.; Okano, T.; Oliveira, J.; Park, T. H.; Penner, R. M.; Prato, M.; Puntes, V.; Rotello, V. M.; Samarakoon, A.; Schaak, R. E.; Shen, Y.; Sjöqvist, S.; Skirtach, A. G.; Soliman, M. G.; Stevens, M. M.; Sung, H.-W.; Tang, B. Z.; Tietze, R.; Udugama, B. N.; VanEpps, J. S.; Weil, T.; Weiss, P. S.; Willner, I.; Wu, Y.; Yang, L.; Yue, Z.; Zhang, Q.; Zhang, Q.; Zhang, X.-E.; Zhao, Y.; Zhou, X.; Parak, W. J. Diverse Applications of Nanomedicine. ACS Nano 2017, 11 (3), 2313-2381.

(108) Alvarez, P. J. J.; Chan, C. K.; Elimelech, M.; Halas, N. J.; Villagrán, D. Emerging opportunities for nanotechnology to enhance water security. Nat. Nanotechnol. 2018, 13 (8), 634-641.

(109) Jacoby, M. The Power of Plastic. Chem. Eng. News 2010, 88 (34), 12-16.

(110) Espinosa, N.; Hösel, M.; Angmo, D.; Krebs, F. C. Solar cells with one-day energy payback for the factories of the future. Energy Environ. Sci. 2012, 5 (1), 5117-5132. 